\title{
Opportunities and Challenges for In-Situ Characterization of Photocatalysts in Environmental TEM.
}

\author{
Liuxian Zhang ${ }^{1}$, Qianlang Liu ${ }^{1}$, Benjamin K. Miller ${ }^{1}$ and Peter A. Crozier ${ }^{1}$ \\ ${ }^{1}$ School for Engineering of Matter, Transport and Energy, Arizona State University, \\ Tempe, AZ, USA
}

Photocatalytic water splitting has been considered a promising technology for generating sustainable clean energy. Essentially, photocatalytic materials enable the process of converting and storing solar energy in the form of $\mathrm{H}_{2}$ molecules. It is now recognized that atomic level in-situ observations of catalytic materials are critical for understanding structure-reactivity relationships and deactivation processes such as photocorrosion. For photocatalysts, this requires that the system be observed not only in presence of reactant and product species but also during in-situ light illumination. Here opportunities and challenges associated with building a "photo-reactor" inside an environmental TEM (ETEM) are discussed.

An optical fiber-based in-situ illumination system was developed and installed in an FEI Tecnai F20 ETEM with light intensity close to 10 suns [1]. The ETEM has a differential pumping system which allows up to 10 Torr gas pressure around the TEM sample. $\mathrm{TiO}_{2}$ based and $\mathrm{Ta}_{2} \mathrm{O}_{5}$ based UV absorption photocatalysts were chosen as model systems for in-situ and ex-situ characterizations. $\mathrm{TiO}_{2}$ is relatively abundant with simple crystal structures while $\mathrm{Ta}_{2} \mathrm{O}_{5}$ is very efficient with more complicated structures. The oxides are functionalized with $\mathrm{Ni}-\mathrm{NiO}$ core-shell nanoparticles, which have been reported to be one of the most efficient surface co-catalysts when loaded onto $\mathrm{TiO}_{2}$ or $\mathrm{Ta}_{2} \mathrm{O}_{5}$. The combination of heat, light, and reactant gas stimuli allows the structural evolution of a photocatalyst to be followed through activation, reaction, and deactivation. Figure 1 shows the activation of a $\mathrm{Ni}$ metal co-catalyst on $\mathrm{TiO}_{2}$ involving in-situ reduction at $400^{\circ} \mathrm{C}$ in 1 Torr for $4 \mathrm{~h}$. Interestingly, the $\mathrm{Ni}$ metal becomes coated with a thin amorphous $\mathrm{TiO}_{\mathrm{x}}$ layer during the reduction step. During the subsequent $\mathrm{Ni}$ oxidation step to form the $\mathrm{Ni}-\mathrm{NiO}$ core-shell structure, this $\mathrm{TiO}_{\mathrm{x}}$ mixes with $\mathrm{NiO}$ layer. Additional experiments have confirmed that the $\mathrm{Ni} / \mathrm{TiO}_{2}$ catalyst reduced ex-situ is also covered with $\mathrm{TiO}_{\mathrm{x}}$ layer.

We have shown that subtle changes may take place under photoreaction conditions. For example, in-situ observation of $\mathrm{TiO}_{2}$ nanocrystals under water and light exposure shows the formation of amorphous surface layers less than $0.5 \mathrm{~nm}$ in thickness [2]. We are currently installing an optical fiber into an FEI Titan ETEM equipped with an image corrector to enable sub-angstrom in-situ imaging of photocatalysts under reaction conditions (using the objective aperture port (Fig. 2)). Using EELS and residual gas analysis to detect gas molecules inside the microscope, we are also pursuing operando TEM to directly detect hydrogen during in-situ illumination of the photocatalysts in a water vapor atmosphere.

For water splitting it is important to understand the difference in deactivation mechanisms under liquid and vapor phase reaction conditions. As shown in Fig. 3, photo corrosion was observed ex-situ as a transformation of the $\mathrm{Ni} / \mathrm{NiO}$ core-shell structure to a void-shell 
structure due to dissolution of $\mathrm{Ni}$ under liquid water and UV exposure from a xenon lamp [3-4]. This photocorrosion mechanism does not occur during in-situ experiments with 18 Torr of water vapor and up to $16 \mathrm{~h}$ UV light exposure. This highlights the difference between liquid and gas phase reaction conditions. For the low pressure conditions present in the differentially pumped ETEM, operando measurements are critical to connect structure and reactivity. For catalytic activity measurements from ex-situ liquid cell photoreactors, in-situ measurement should ideally be performed in a liquid cell environment to correlate structure and reactivity. Practical issues including electron beam effects, light source alignment, sample stability, etc. must also be understood and controlled. This presentation will discuss many of the technical and scientific opportunities and challenges for in-situ characterization of photocatalysts with emphasis on solar hydrogen production.

\section{References:}

[1] B.K. Miller et al, Microscopy and Microanalysis 2013, 19, 461-469

[2] L. Zhang et al, Nano Lett. 201313 (2), 679-684

[3] Q. Liu et al, Appl. Catal. B 2015 172-173, 58-64

[4] L. Zhang et al, J. Phys. Chem. (under review)

[5] The support from US Department of Energy (DE-SC0004954) and the National

Science Foundation (CBET-1134464) and the use of TEM at John M. Cowley Center for HR Microscopy at Arizona State University is gratefully acknowledged.

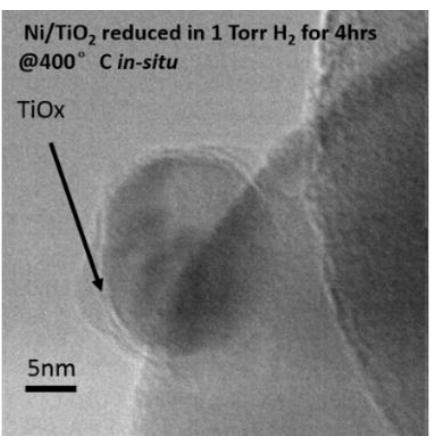

Figure $1 \mathrm{Ni} / \mathrm{TiO}_{2}$ reduced in 1 Torr flowing $\mathrm{H}_{2}$ for $4 \mathrm{~h}$ in-situ

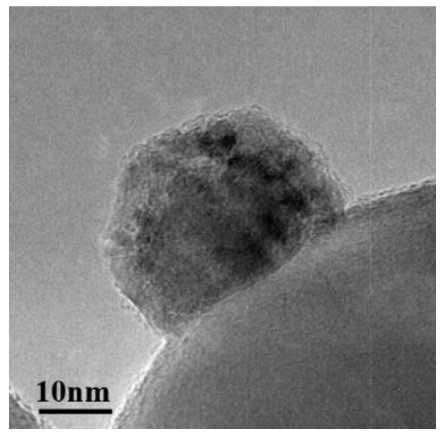

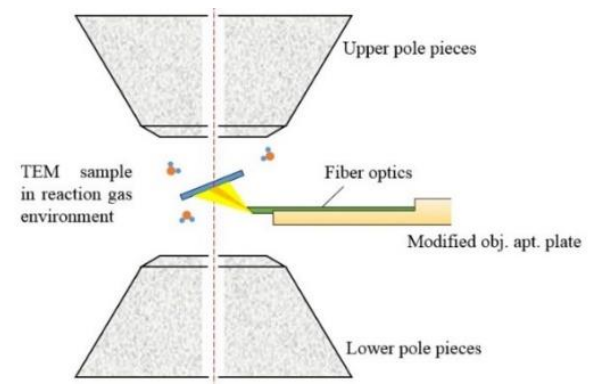

Figure 2 Schematic drawing of the development of light illumination system on objective aperture rod for FEI TITAN

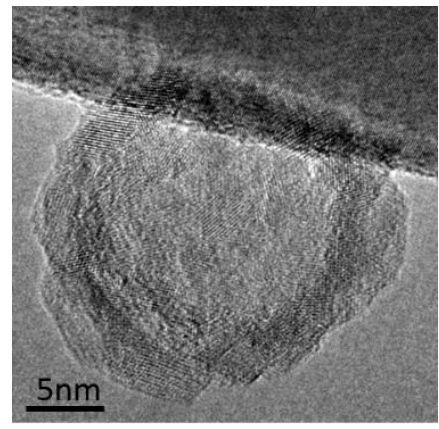

Figure 3: a) $\mathrm{Ni}-\mathrm{NiO}$ core-shell structure maintained after $16 \mathrm{~h}$ water vapor and light exposure in-situ. b) Ni-NiO core-shell structure transformed to void-shell after ex-situ exposure of $6 \mathrm{~h}$ light exposure in liquid water. 